\title{
Compartmental Human Respiratory Tract Modeling of Airborne Dust Exposure from Feeding in Swine Buildings
}

\author{
Jein-Wen Chen, Chung-Min Liao, and Szu-Chieh Chen \\ Department of Bioenvironmental Systems Engineering, National Taiwan University, Taipei, Taiwan
}

\begin{abstract}
A simple size-dependent compartmental model was developed to describe airborne dust exposure dynamics for the human respiratory tract (HRT) in mechanically ventilated swine buildings. Transport mechanisms of airborne dust for HRT include respiration, gravitational settling, turbulent diffusive deposition, inertial impaction, interception deposition loss, and dust clearance. The dominant deposition mechanism in the lung regions was found to be the inertial impaction rate, in which the order of magnitude ranged from $10^{-3}$ to $10^{-1} \mathrm{sec}^{-1}$. Results demonstrate that the extrathoracic region has a higher airborne dust mass lung/indoor ratios (0.71-0.87) than do the bronchial regions (0.41-0.74), the bronchiolar region $(0.12-0.61)$, and the alveolar-interstitial region (0.01-0.49). The predictions from the HRT model agreed favorably with the experimental deposition profiles in the nasal passage, pharynx, bronchial, bronchiolar, and alveolar-interstitial regions, whereas the rms errors of the total deposition fraction between predicted values and ICRP66 and Non-ICRP66 were 0.15 and 0.07 , respectively. Simulation results show that breathing via the nose has both a higher deposition fraction and a higher exposure dose in the size ranges 0.01-10 $\mu \mathrm{m}$ than does breathing orally.
\end{abstract}

\section{INTRODUCTION}

Dust is one of the main contaminants in swine buildings and results from animal activity, air movement, finely

\section{IMPLICATIONS}

The lung model in this work provides a simple yet robust way to calculate and keep track of the contribution of different processes of lung deposition profiles. The dust size distributions, mass and number concentrations, and inhaled exposure dose are obtained in five major regions of the HRT when breathing through the nose or mouth. Mathematical models provide an option for analysis of lung deposition yet may be used for regulatory policy development. ground dry feed introduced during feeding, and fecal-feed particles deposited on a solid floor and later entrained into the air. ${ }^{1-3}$ The majority of particles are of fecal origin, and the major proportion (85\%) of the dust mass in swine buildings is from feed particles. ${ }^{4,5}$ The majority of dust particles found in animal housing have a diameter that ranges between 0.5 and $5 \mu \mathrm{m} .{ }^{6-8}$ Maghirang et al. ${ }^{9}$ indicated that there is some evidence of particles larger than $10 \mu \mathrm{m}$ found in a swine nursery that have a lognormal distribution with geometric mean diameter (GMD) of 8 $\mu \mathrm{m}$ and a geometric standard deviation (GSD) of 3. Based on the measurements of Gao and Feddes, ${ }^{6}$ a lognormal distribution with a GMD of $2 \mu \mathrm{m}$ and a GSD of 1.65 was found.

Respiratory diseases have long been recognized to be associated with farming, and farmers are known to have high morbidity and mortality from certain respiratory diseases. ${ }^{10}$ Agricultural/animal farmers have more complaints of work-related symptoms from the lower airways $^{11}$ and symptoms of smell impairment, and more often have nasal polyps and hyperemia of the nasal mucosa. ${ }^{12}$ An investigation of the relation between lung function and exposure assessment to organic dust indicated that temperature and ventilation of the animal houses might influence respiratory morbidity in farmers. ${ }^{13}$

Development of respiratory disorders has been reported to be associated with working in swine confinement buildings. ${ }^{14-17}$ Endotoxin, swine dust, and toxic gases that are identified in the air of piggeries are considered to be the important causes. ${ }^{18-21}$ Exposure to airborne swine dust above $2.5 \mathrm{mg} / \mathrm{m}^{3}$ is reported to be associated with symptoms of respiratory diseases ${ }^{22}$ and a decrease in $\mathrm{FEV}_{1}$ (forced expiratory volume at $1 \mathrm{sec}$ ). 7,23 There is extensive evidence to suggest that exposure to increased levels of inhalable particulate pollutants is associated with increases in mortality and morbidity from cardiovascular and respiratory causes. ${ }^{24-27}$

A complete particle exposure model for the human respiratory tract (HRT) will include airflow dynamic, physiological, lung morphological, and dose-cumulated submodels. In general, numerous mathematical models 
for predicting particle deposition in the human airway can be classified into three major groups. The first follows an approach based on the concept of applying compartmental modeling to human lung anatomy. In the second approach, the human lung is modeled as a chamber shaped like a trumpet with a variable crosssectional area, and the third approach used a combination of theoretical and empirical expressions to predict particle deposition in HRT, ${ }^{28}$ whereas the third approach was suggested by ICRP66.29 Jacquez $^{30}$ further indicated that the compartmental model was used in biology and can be found in such diverse areas as epidemiology, pharmacokinetics, intermediary metabolism, carcinogenesis, mutation rate and evolution, and physical sciences.

The purposes of this study are twofold: (1) to determine the airborne dust mass lung/indoor (L/I) ratio under steady-state based on the measurements of airborne dust characteristics, including size distribution patterns, mass, and number concentrations in swine buildings, and (2) to calculate the deposition fractions and exposure dose of airborne dust for different HRT regions that can be used for developing risk analysis of long-term inhalation in livestock buildings.

\section{MODEL DEVELOPMENT}

\section{Airborne Dust Deposition Model}

HRT was divided into five major compartments from the suggestion of ICRP66 ${ }^{21}$ (Figure 1): (1) the nasal passage $\left(\mathrm{ET}_{1}\right)$, comprising the anterior nose and the posterior nasal passages; (2) the pharynx $\left(\mathrm{ET}_{2}\right)$, comprising the larynx and mouth; (3) the bronchial region (BB), comprising the airway from the trachea, main bronchi, and intrapulmonary bronchi; (4) the bronchiolar region (bb), comprising the bronchioles and terminal bronchioles; and (5) the alveolar-interstitial region (AI), comprising the airway from the respiratory bronchioli through the alveolar sacs.

Before deriving the system dynamic equations to describe the concentration changes of airborne dust over time within HRT, the following assumptions were made: (1) every compartment is assumed to be a complete mixing system; (2) airborne dust is treated as an aerodynamic equivalent sphere and is electrically neutral; (3) no gas-to-dust conversion occurs within the system; (4) HRT is treated as a circular tube and has the same physiological characteristics within the same compartment; (5) turbulent coagulation and hygroscopicity of the dust phase are neglected; and (6) air volume changes caused by oxygen demand in HRT are neglected.

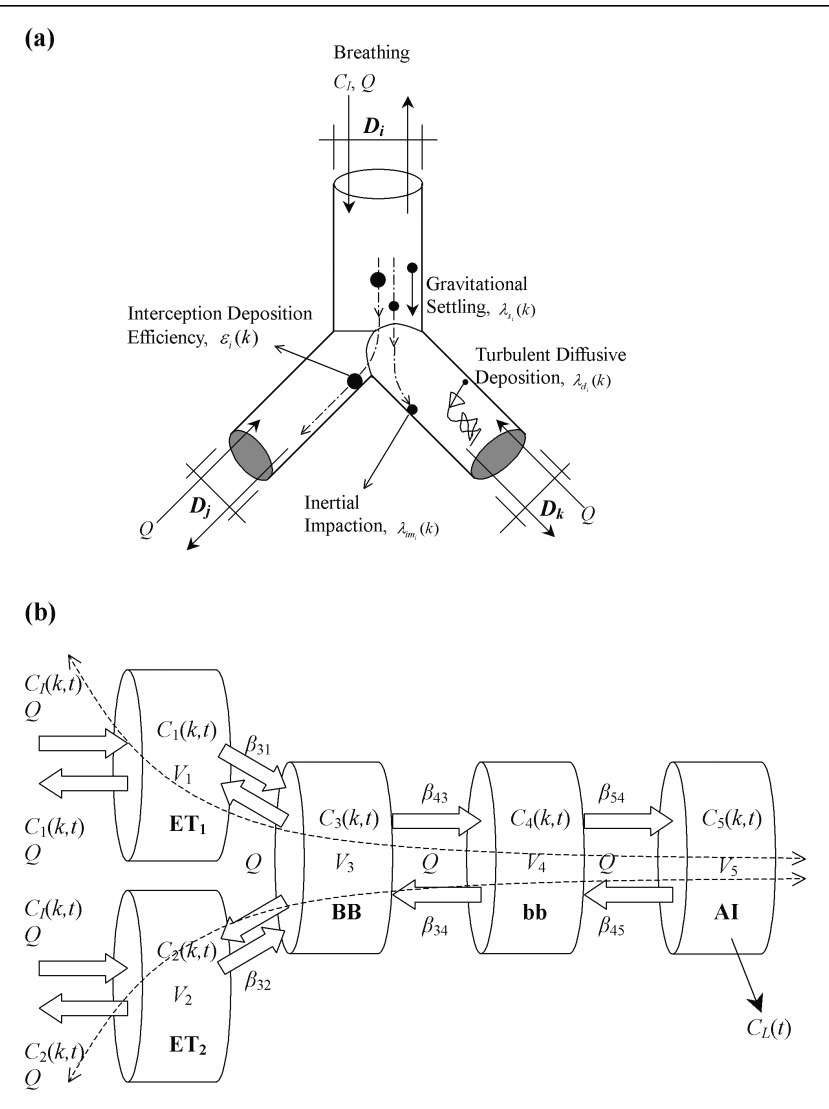

Figure 1. Airborne dust transport behaviors in HRT. (a) The transport mechanisms include respiration, turbulent diffusive deposition, gravitational settling, inertial impaction, and interception deposition efficiency. (b) The five major compartments in HRT are the nasal passage $\left(E T_{1}\right)$, the pharynx $\left(\mathrm{ET}_{2}\right)$, bronchial (BB), bronchiolar (bb), and alveolar-interstitial (Al) regions.

Combining the physical and physiological processes controlling the gain and loss rates yields the dynamics equations that describe the concentration trajectory of airborne dust in HRT. Followed by the principle of mass balance, the dynamic equations of the inspiratory oral cavity (IOC) varying with dust size range $k$ and time $t$ to each regional compartment are given by a state-space realization form of a linear dynamic representation as

$$
\left\{\frac{d C(k, t)}{d t}\right\}=[L]\{C(k, t)\}[B]\{u(k, t)\}
$$

where $\{u(k, t)\}=\left\{C_{1}(k, t) C_{3}(k, t) C_{4}(k, t) C_{5}(k, t)\right\}^{\mathrm{T}}$ is the state variable vector of dust concentrations in compartments $\mathrm{ET}_{1}, \mathrm{BB}, \mathrm{bb}$, and $\mathrm{AI}$, respectively; $\{u(k, t)\}=\left\{C_{1}(k, t) \quad 0 \quad 0 \quad 0\right\}$ represents an input vector of dust concentration $\left(\mathrm{cm}^{-3}\right)$; whereas the state matrix $[L]\left(\mathrm{sec}^{-1}\right)$ and the constant input matrix $[B]\left(\mathrm{sec}^{-1}\right)$ have the following forms, respectively, as $[L]=$ 


$$
\left[\begin{array}{cc}
\lambda_{\mathrm{d}_{1}}(k) \lambda_{\mathrm{s}_{1}}(k) \lambda_{\mathrm{im}}(k) & \\
\varepsilon_{1}(k) \frac{Q}{V_{1}} \beta_{31} \frac{Q}{V_{1}} \frac{Q}{V_{1}} & \beta_{13} \frac{Q}{V_{1}} \\
\beta_{31}\left(\frac{Q}{V_{3}}\right. & \varepsilon_{3}(k) \frac{Q}{V_{3}} \beta_{43} \frac{Q}{V_{3}}(k) \lambda_{\mathrm{im}_{3}}(k) \\
0 & \beta_{43} \frac{Q}{V_{3}} \\
0 & 0
\end{array}\right.
$$

and

$$
[B]=\operatorname{diag}\left[Q / V_{1}, 0,0,0\right],
$$

where $C_{1}(k, t), C_{3}(k, t), C_{4}(k, t)$, and $C_{5}(k, t)$ are the timedependent airborne dust concentrations in the $k$ th size range within compartments $\mathrm{ET}_{1}, \mathrm{BB}, \mathrm{bb}$, and $\mathrm{AI}$, respectively $\left(\mathrm{cm}^{-3}\right) ; C_{\mathrm{I}}(k, t)$ is the airborne dust concentration in the $k$ th size range within swine building; $Q$ is the breathing rate $\left(\mathrm{cm}^{3} / \mathrm{hr}\right) ; V_{\mathrm{i}}$ is the volume of compartment $i$ $\left(\mathrm{cm}^{-3}\right) ; \lambda_{\mathrm{d}}(k), \lambda_{\mathrm{s}}(k)$, and $\lambda_{\mathrm{nm}}(k)$ represent turbulent diffusive deposition rate, gravitational settling rate, and inertial impaction rate, respectively, in the $k$ th size range in the compartment $i\left(\mathrm{sec}^{-1}\right) ; \varepsilon_{\mathrm{i}}(k)$ is the interception deposition efficiency in the $k$ th size range in the compartment $i ; \beta_{\mathrm{nm}}$ is the transition coefficient from compartments $n$ to $m ; \lambda_{\mathrm{L}}(t)$ is the time-dependent airborne dust clearance rate in the compartment $\mathrm{AI}\left(\mathrm{sec}^{-1}\right)$; and $k$ is the size range number.

The dust is divided into geometrically equal-sized bins in the size range of interest. The airborne dust concentration is assumed to be a constant aerodynamic equivalent diameter (AED) within each bin size. The end points, $d_{\mathrm{k}}$ and $d_{\mathrm{k}+1}$, of the $k$ th bin size are considered to be equal to the geometric mean of the end points of the bin size as

$$
d_{\mathrm{k}} d_{\text {min }}=\frac{\left(d_{\text {max }} d_{\text {min }}\right)(k 1)}{N 1}, k 1,2, \ldots, N
$$

where dust smaller than $d_{\text {min }}$ (the minimum diameter) is considered to be the finest, and $d_{\max }$ is the largest dust size of interest; and $N$ is assigned to be the end point number for a $k$ th size range, $d_{\mathrm{k}}$ and $d_{\mathrm{k}+1}$.

Equation 1 can be solved explicitly as airborne dust concentrations reach steady-state. The diagonal element $L_{\mathrm{ii}}$ in matrix $[L]$ is defined as $L_{\mathrm{ii}}=L_{\mathrm{ii}}(k)$ and yields the dust indoor-personal exposure relationships corresponding to the $\mathrm{L} / \mathrm{I}$ mass ratio in each compartment as

$$
\left.\begin{array}{cc}
0 & 0 \\
\beta_{34} \frac{Q}{V_{3}} & 0 \\
\lambda_{\mathrm{d}_{4}}(k) \lambda_{\mathrm{s}_{4}}(k) \lambda_{\mathrm{im}_{4}}(k) & Q \frac{Q}{V_{4}} \beta_{54} \frac{Q}{V_{4}} \beta_{34} \frac{Q}{V_{4}} \\
\varepsilon_{4}(k) \frac{\beta_{45} \frac{Q}{V_{4}}}{\lambda_{\mathrm{d}_{5}}(k) \lambda_{\mathrm{s5}}(k) \lambda_{\mathrm{im} 5}(k)} \\
\beta_{54} \frac{Q}{V_{5}} & \varepsilon_{5}(k) \frac{Q}{V_{5}} \beta_{45} \frac{Q}{V_{5}} C_{\mathrm{L}}(t)
\end{array}\right]
$$

$$
\frac{C_{1}(k)}{C_{1}(k)}=\frac{\frac{Q}{V_{1}} \cdot\left(L_{33} \cdot L_{44} \cdot L_{55} L_{33} \cdot \beta_{45} \frac{Q}{V_{4}} \beta_{54} \frac{Q}{V_{5}} L_{55} \cdot \beta_{34} \frac{Q}{V_{3}} \cdot \beta_{43} \frac{Q}{V_{4}}\right)}{\Delta_{k}},
$$

$$
\frac{C_{3}(k)}{C_{1}(k)}=\frac{\frac{Q}{V_{1}} \cdot \beta_{31} \frac{Q}{V_{3}} \cdot\left(L_{44} \cdot L_{55} \beta_{45} \frac{Q}{V_{4}} \cdot \beta_{54} \frac{Q}{V_{5}}\right)}{\Delta_{\mathrm{k}}},
$$

$$
\begin{gathered}
\frac{C_{4}(k)}{C_{1}(k)}=\frac{\frac{Q}{V_{1}} \cdot \beta_{31} \frac{Q}{V_{3}} \cdot \beta_{43} \frac{Q}{V_{4}} \cdot L_{55}}{\Delta_{\mathrm{k}}}, \\
\frac{C_{5}(k)}{C_{1}(k)}=\frac{\frac{Q}{V_{1}} \cdot \beta_{31} \frac{Q}{V_{3}} \cdot \beta_{43} \frac{Q}{V_{4}} \cdot \beta_{54} \frac{Q}{V_{5}}}{\Delta_{\mathrm{k}}},
\end{gathered}
$$

where $C_{\mathrm{i}}(k) / C_{1}(k), i=1,2,3,4,5$ represents the dust $\mathrm{L} / \mathrm{I}$ ratios for compartments $\mathrm{ET}_{1}, \mathrm{ET}_{2}, \mathrm{BB}, \mathrm{bb}$, and $\mathrm{AI}$, respectively, and

$$
\Delta_{\mathrm{k}}=[L(k)]=\left[\begin{array}{cccc}
L_{11}(k) & \beta_{13} \frac{Q}{V_{1}} & 0 & 0 \\
\beta_{31} \frac{Q}{V_{3}} & L_{33}(k) & \beta_{34} \frac{Q}{V_{3}} & 0 \\
0 & \beta_{43} \frac{Q}{V_{4}} & L_{44}(k) & \beta_{45} \frac{Q}{V_{4}} \\
0 & 0 & \beta_{54} \frac{Q}{V_{5}} & L_{55}(k)
\end{array}\right] .
$$

\section{Parameterization of Rate Equations}

Solution of eq 1 requires that the sink rate over the various $k$ th size ranges be estimated as

$$
\lambda_{\mathrm{d}}(k)=\frac{1}{d_{\mathrm{k} 1} d_{\mathrm{k}}} \int_{\mathrm{d}_{\mathrm{k}}}^{\mathrm{d}_{\mathrm{k} 1}} \lambda_{\mathrm{d}}\left(d_{\mathrm{p}}\right) d\left(d_{\mathrm{p}}\right) .
$$


Parametric forms for the turbulent diffusive deposition, gravitational settling and inertial impaction rates, and interception deposition efficiency used in the interaction algorithm of the dynamic model are given in Table 1 . The role of each rate equation will be investigated.

Turbulent Diffusive Deposition Rate. Diffusional deposition from turbulent flows in this work is calculated from Crump and Seinfeld ${ }^{31}$ and is referred to as the C-S model. The C-S model is a well-established general model for the rate of dust deposition caused by turbulent diffusion, Brownian diffusion, and gravitational settling in a turbulently mixed enclosure of arbitrary shape. Applying the C-S model to a cylindrical enclosure, eq 8 is obtained by modifying the C-S model to describe the turbulent diffusive deposition rate of a specific dust diameter, $d_{\mathrm{p}}$. The diffusivity of dust is inversely proportional to dust diameter, $d_{\mathrm{p}}$. The turbulent parameters $\left(k_{\mathrm{e}}\right.$ and $\left.n\right)$ were estimated by assuming complete turbulent dissipation of the input energy. ${ }^{32,33}$

Gravitational Setting Rate. Equation 11 represents the gravitational settling rate of a specific dust diameter, $d_{\mathrm{p}}$, and is obtained from the C-S model as well as the turbulent diffusive deposition rate in a cylindrical enclosure. The terminal settling velocity increases rapidly with dust size, being proportional to the square of the dust diameter. The physiological factor that influences both turbulent diffusive deposition and gravitational settling rate in this work is the diameter of the airway in each compartment region.

Inertial Impaction Rate. Inertial impaction of dust with a specific diameter, $d_{\mathrm{p}}$, on the airway walls in bifurcation

Table 1. Rate equations of dust deposition for HRT. (The description of symbols is given in the appendix).

Turbulent Diffusive Deposition Rate

\begin{tabular}{|c|c|}
\hline $\begin{array}{l}\lambda_{\text {di }}\left(d_{p}\right)=8 / D_{\mathrm{p}} \sin \pi / n\left[k_{\mathrm{p}} D\left(d_{\mathrm{p}}\right)^{n-1}\right]^{1 / n} \\
\text { where }\end{array}$ & $(8)^{a}$ \\
\hline$D\left(d_{\mathrm{p}}\right)=k_{\mathrm{B}} T C_{\mathrm{silp}} / 3 \pi \eta_{\mathrm{a}} d_{\mathrm{p}}$ & $(9)^{b}$ \\
\hline $\begin{array}{l}C_{\text {slip }}=\left[1=\lambda / d_{p}\left(2.541+0.8 \exp \left(-0.55 d_{p} / \lambda\right)\right)\right] \\
\text { Gravitational Settling Rate }\end{array}$ & $(10)^{b}$ \\
\hline $\begin{array}{l}\lambda_{\mathrm{si}}\left(d_{\mathrm{p}}\right)=4 v_{\mathrm{s}}\left(d_{\mathrm{p}}\right) / D_{\mathrm{i}} \operatorname{coth}\left[\pi v_{\mathrm{s}}\left(d_{\mathrm{p}}\right) / 2(n \sin \pi / n)\left(k_{\mathrm{e}} D\left(d_{\mathrm{p}}\right)^{\mathrm{n}-1}\right)^{1 / n}\right] \\
\text { where }\end{array}$ & $(11)^{\mathrm{a}}$ \\
\hline $\begin{array}{l}v_{s}\left(d_{p}\right)=\rho_{p} g d_{p}^{2} / 18 \eta_{a} C_{\text {silp }}\left(1-\rho_{a} / \rho_{p}\right) \\
\text { Inertial Impaction Rate }\end{array}$ & $(12)^{b}$ \\
\hline $\begin{array}{l}\lambda_{\text {imi }}\left(d_{p}\right)=\rho_{p} d_{p}^{2} C_{\text {slip }} g / 9 \eta_{a} D_{i}=S t k g / U_{i} \\
\text { Interception Deposition Efficiency }\end{array}$ & $(13)^{b}$ \\
\hline $\begin{array}{l}\varepsilon_{i}\left(d_{p}\right)=(1-\alpha) n_{i} / \sum n_{i} d_{p} / d / / K u\left(1+d_{p} / D_{i}\right) \\
\text { where }\end{array}$ & $(14)^{b}$ \\
\hline$K u=-\ln \alpha / 2-3 / 4+\alpha-\alpha^{2} / 4$ & $(15)^{b}$ \\
\hline
\end{tabular}

adopted from Crump and Seinfeld; 31 b Adopted from Hinds. 32 zones is accounted for by eq 13 for dust collection efficiency in smooth bends. The parameter that governs collection efficiency is the Stokes number, or impaction parameter, which is defined for an impactor as the ratio of the dust-stopping distance at the exit velocity $U$ to the airway radius, $D_{\mathrm{i}} / 2$.

Interception Deposition Efficiency. Interception occurs when the dust hits the airway wall and is captured because of its finite size. For pure interception, it is assumed that the dust follows the streamlines perfectly and has negligible inertia, settling, and Brownian motion. The single-dust efficiency for interception with dust diameter, $d_{\mathrm{p}}$, is given by Hinds, ${ }^{34}$ considering the interception within overall airways can obtain eq 14 to describe the interception deposition efficiency whereas Kuwabara hydrodynamic factor, a dimensionless factor that compensates for the effect of distortion of the flow field around a dust. Interception is the only mechanism that is not a result of a dust departing from its original flow field streamline.

\section{Deposition Fraction}

Calculation of dust deposition in HRT is required to evaluate the size-resolved loss term in eq 1 . Turbulent diffusive deposition, gravitational settling, inertial impaction rate, interception deposition, and dust clearance are the dust-deposition mechanisms addressed in this study. The deposition fraction is calculated from the formula

$$
d_{\mathrm{F}}(k)=\frac{C_{\mathrm{i}}(k)}{C_{\mathrm{I}}(k)}\left[\left(\lambda_{\mathrm{d}_{\mathrm{i}}}(k) \lambda_{\mathrm{s}_{\mathrm{i}}}(k) \lambda_{\mathrm{im}_{\mathrm{i}}}(k)\right) \cdot \frac{V}{\mathrm{Q}} \varepsilon_{\mathrm{i}}(k)\right]
$$

where $C_{\mathrm{i}}(k), i=1,2,3,4,5$; and $d_{\mathrm{F}}(k)$ is the dust deposition fraction of each lung region in the $k$ th size range.

\section{Inhalation Dose Model}

The time-dependent concentration profiles of dust are used to calculate exposure doses through inhalation and are represented as

$$
D_{\mathrm{d}}(k, t)=\frac{\int_{0}^{\mathrm{t}} C_{\mathrm{i}}(k, t) \cdot d_{\mathrm{F}}(k) \cdot \mathrm{Qd} t}{A_{\mathrm{i}}}
$$

where $D_{\mathrm{d}}(k, t)$ is the time-dependent cumulative inhalation dose of dust per unit area of each lung region in the $k$ th size range $\left(\mu \mathrm{g} / \mathrm{cm}^{2}\right)$; and $A_{\mathrm{i}}$ is the surface area of airway wall in the compartment $i\left(\mathrm{~cm}^{2}\right)$. The differences in exposure can vary because of factors such as diameter of airways, breathing rate, dust profile, and time spent in the swine buildings. The time-dependent size distribution of dust from the dynamic model of eq 1 was combined 
with the inhalation dose model (eq 17) for the size-dependent dose to obtain the integrated inhalation dose as a function of size.

\section{Uncertainty Analysis}

Because of limitations in the data and to support measured dust concentrations in swine buildings and in HRT, there is a need to characterize uncertainty and variability in the model approach and input parameters. A Monte Carlo approach was applied to appraise the impact of parameter uncertainty on the experiment results. To express uncertainty in indoor dust concentration, the Kolmogorov-Smirnov (K-S) statistics were employed to optimize the goodness-of-fit of distributions. To analyze data and to estimate distribution parameters, we employed @RISK (Version 4.5, Professional Edition, Palisade Corp.). Results from goodness-of-fit statistics suggest that the normal distribution model fits the observed data. To calculate the airborne dust mass L/I ratio for each lung compartment, we employed 95th-percentile predictions of the indoor dust level as the conservatism values. ${ }^{35}$

\section{Numerical Schemes}

Integration over time of eq 1 is straightforward in principle but is complicated by the existence of a large number of widely differing time scales. The number of independent variables is $4 N+1$, where $N$ is the number of bins in the size range of interest. The numerical integration scheme used to solve the system dynamic eq 1 is a subroutine DIVPRK based on the Runge-Kutta-Verner 4thorder and 5th-order method, whereas a subroutine QDAG based on Gauss-Legendre formulas is adopted to solve eq 17. Both subroutines are provided by IMSL Subroutines Library ${ }^{36}$ and done in double precision with FORTRAN 90. The algorithm is stable provided the error and the convergence criterion are monitored carefully.

\section{EXPERIMENT}

An experiment was carried out to characterize the dustsize distributions and dust levels for the existing ambient airborne dust during feeding and nonfeeding periods. A growing swine building situated at Tainan, a southern Taiwan region, was chosen as the study area. Measurements were conducted in a fan-ventilated swine building (Figure 2). The building had a semi-slatted floor and measured $24 \times 9.2 \times 2 \mathrm{~m}$. There were two manure pits measuring $1 \times 23 \mathrm{~m}$ on each side of the building. Six $4 \times 4 \mathrm{~m}$ pens on each side of the building were separated by a 1.2-m-wide service alley. Two 0.9-m-diameter fans located at each end of the building with continuous slot eave inlets provide summer ventilation. During the experiment, both fans were operated continuously. Building ventilation rates, determined using the impeller method (a)

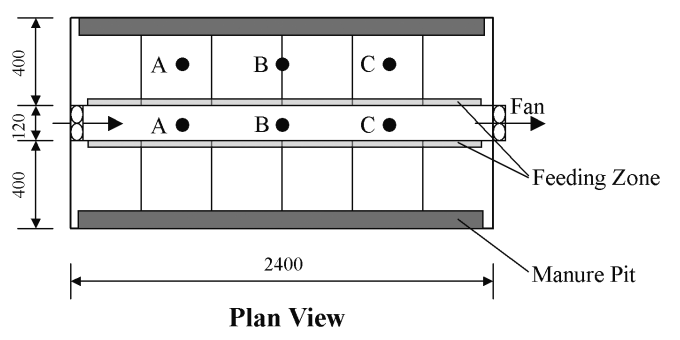

(b)

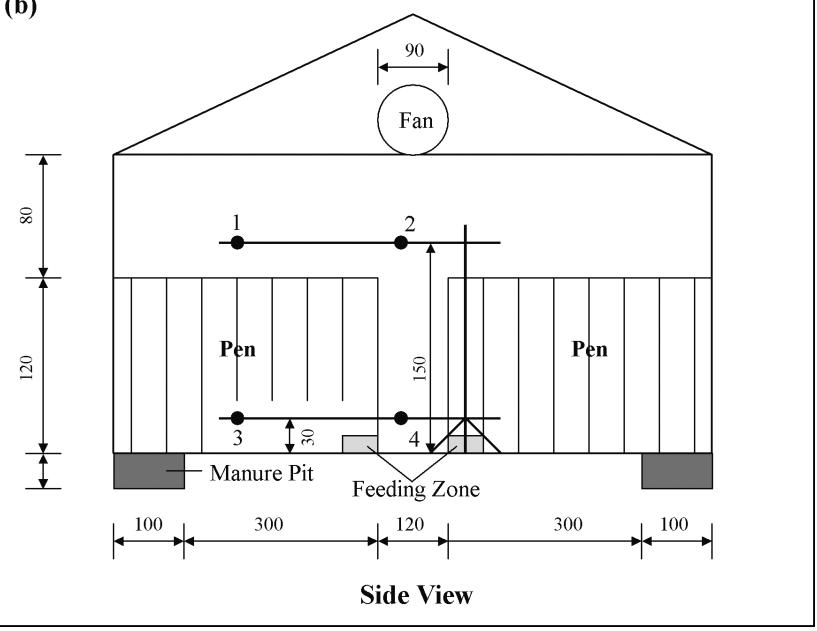

Figure 2. The Tainan swine building showing the sampling locations (a): (a) plan view, and (b) side view. All dimensions are in centimeters.

based on the manufacturer specification, were $\sim 845$ and $280 \mathrm{~m}^{3} / \mathrm{hr}$, respectively, during feeding and nonfeeding periods. There were 150 pigs at a stocking density of 10-15 pigs/pen. Indoor air temperature and relative humidity was measured to be $29 \pm 1.5{ }^{\circ} \mathrm{C}$ and $65 \pm 3 \%$, respectively.

Dust sampling was conducted for five sampling days. Monitoring commenced when the pigs were 150 days old (mean pig weight $=70 \mathrm{~kg}$ ). A portable laser dust monitor (Series 1100, Grimm Labortechnik GmbH \& Co. KG; referred to as DM1100) was used to analyze the ambient airborne dust characteristics. The DM1100 combines the principles of aerodynamic dust size separation and lightscattering particle detection. The aerodynamic characteristics of an equivalent aerodynamic size of the dust can range from 0.5 to $10 \mu \mathrm{m}$. The DM1100 measured dust mass concentrations in the range of $1-50,000 \mu \mathrm{g} / \mathrm{m}^{3}$. Measured channels are in the ranges of $0.5-1,1-2,2-5$, $5-10$, and $>10 \mu \mathrm{m}$ AED. The DM1100 was operated for 24 $\mathrm{hr}$ at the design sampling flow rate of $1.2 \mathrm{~L} / \mathrm{min} \pm 10 \%$. Before the measurements, the DM1100 was calibrated with known particles of Uniform Latex Microspheres Polystyrene $(0.5 \mu \mathrm{m})$ and Polymer Microspheres Styrene Vinyltoluene $(3 \mu \mathrm{m})$ (Duke Scientific). The sampling interval was divided into three periods: 06:00-07:00 
(first feeding period), 07:0018:00 (nonfeeding period), and 18:00-19:00 (second feeding period).

\section{INPUT PARAMETER Number of Bins and Size Ranges}

The size range, $0-5 \mu \mathrm{m}$, was divided into five geometrically equal-size bins based on eq 2 in this work, and resulting values of the average particle diameter were $0.95,1.85,2.75,3.65$, and $4.55 \mu \mathrm{m}$ for bins $1,2,3,4$, and 5 , respectively.

\section{Lung Physiological Parameters}

The major route of entry into the body of airborne dust in the swine building is inhalation, and this causes deposition and accumulation in HRT. The extrathoracic airways, including the nasal passage and the oral passage (because humans breathe through their noses and their mouths) are the first targets for inhaled dusts as well as an important defense for HRT by reducing the dust number to the more distal airways. Inspiratory/expiratory oral cavity (IOC/ EOC) and inspiratory/expiratory nasal-pharyngeal (INP/ ENP) were treated as the breathing patterns during feeding and nonfeeding periods, respectively. Other physiological parameters, including clearance rate, transfer coefficient between lung compartments, and airways reference values, are obtained from ICRP66. ${ }^{29}$

\section{Deposition Rate Parameters}

In the turbulent diffusive deposition and gravitational settling rate, the value of the exponent $(n)$ was chosen to be 2,33 and the value of the turbulent intensity parameter, $k_{\mathrm{e}}$, was set equal to $0.5 \mathrm{sec}^{-1}$ to correspond to the eddy and turbulent fluid. ${ }^{32,33}$ There will be some coupling between the rate of breathing and the degree of turbulence. This coupling, however, is expected to be small for breathinduced turbulence and was neglected in the model. ${ }^{32,33}$ It was not possible to estimate the change in $k_{\mathrm{e}}$ in such a situation, and that scenario was not considered.

Table 2 summarizes the values of all input parameters appearing in the lung models. Because the goal of this work is to examine the dynamic contribution to exposure dose from feedings, the initial conditions for the airborne dust concentrations in HRT for all the simulations were assumed to be zero. Table 3 summarizes the operating parameters used in the model simulations. The ambient dust profile was assumed to be time-independent during each individual simulation.

\section{RESULTS}

Experimental results show that the particle size distributions followed a lognormal distribution with a geometric mean diameter (GMD) (which is based on number) of $2.17 \pm 0.06$ and $2.11 \pm 0.05 \mu \mathrm{m}$ and a geometric standard deviation (GSD) of $1.75 \pm 0.05$ and $1.71 \pm 0.06$ during feeding and nonfeeding periods, respectively. The mean

Table 3. Operating parameters used in the HRT model simulation.

\begin{tabular}{lcc}
\hline \hline & $\begin{array}{c}\text { Feeding } \\
\text { Periods }\end{array}$ & $\begin{array}{c}\text { Nonfeeding } \\
\text { Period }\end{array}$ \\
\hline Breathing rate $\left(\mathrm{m}^{3} / \mathrm{hr}\right)$ & 3.6 & 1.2 \\
Dust profile & & \\
Particle size distribution ${ }^{\mathrm{a}}$ & $\mathrm{LN}(2.17 \mu \mathrm{m}, 1.75)$ & $\mathrm{LN}(2.11 \mu \mathrm{m}, 1.71)$ \\
Particle number concentration $\left(\mathrm{cm}^{-3}\right)$ & 6567 & 592 \\
Particle mass concentration $\left(\mathrm{mg}^{3} \mathrm{~m}^{3}\right)$ & 33.6 & 3.06 \\
Dust concentration in each bin & & \\
$\quad$ (particle/ $\left./ \mathrm{cm}^{3}\right)$ & & 71 \\
Bin 1 $(0.5-1.4 \mu \mathrm{m})$ & 789 & 265 \\
Bin 2 $(1.4-2.3 \mu \mathrm{m})$ & 2955 & 120 \\
Bin 3 $(2.3-3.2 \mu \mathrm{m})$ & 1313 & 88 \\
Bin 4 $(3.2-4.1 \mu \mathrm{m})$ & 985 & 48 \\
Bin 5 $(4.1-5 \mu \mathrm{m})$ & 525 & \\
\hline \hline
\end{tabular}

${ }^{a} \mathrm{LN}(\boldsymbol{\mu}, \boldsymbol{\sigma})$ represents the lognormal distribution with geometric mean diameter $\boldsymbol{\mu}$ and geometric standard deviation $\sigma$ 
total dust mass concentrations were $20.47 \pm 8.23 \mathrm{mg} / \mathrm{m}^{3}$ (ranging from 7.53 to $36.01 \mathrm{mg} / \mathrm{m}^{3}$ ) and $2.32 \pm 0.45$ $\mathrm{mg} / \mathrm{m}^{3}$ (ranging from 1.76 to $3.35 \mathrm{mg} / \mathrm{m}^{3}$ ), respectively, for feeding and nonfeeding periods. The result from the chamber test shows that the particle size distribution of the feed collected in the swine building is $\operatorname{LN}(2.13,1.7)$, indicating that feed dust was the main source of the airborne dust. The airborne dust mass concentrations in the Tainan swine building are presented in Figure 3, whereas the box and whisker plots represent the uncertainty in that the employed 95th-percentile prediction values of dust level are 33.60 and $3.06 \mathrm{mg} / \mathrm{m}^{3}$ for feeding and nonfeeding periods, respectively. A comparison with the published data $\left(9-18.6 \text { particles } / \mathrm{cm}^{3}\right)^{7}$ shows that the magnitude of the number concentrations observed in the Tainan swine building appears to be extremely high. The high values might be related to the feeding strategy and feedstuff used in the Tainan swine building.

The number distribution patterns in HRT have no significant variation in feeding and nonfeeding periods but have a different number concentration resulting from the indoor ambient dust number (Figure 4). Because the airborne dust concentrations within the five compartments reach the steady state in 5-10 sec for all the size ranges, it is more important to understand the airborne dust mass L/I ratio, deposition fraction, and inhalation exposure dose than the dynamics of airborne dust in HRT. Comparing the concentrations in $\mathrm{ET}_{1}$ with $\mathrm{AI}$ compartments, the deeper lung region has a lower airborne dust concentration because the deposition makes the dust no longer airborne, especially in the larger size range, bin 4 (3.2-4.1 $\mu \mathrm{m})$ and bin $5(4.1-5 \mu \mathrm{m})$ (see Figure 4$)$.

Generally, the region AI has higher deposition rates than do regions $\mathrm{ET}_{1} / \mathrm{ET}_{2}, \mathrm{BB}$, and $\mathrm{bb}$. The lung region $\mathrm{ET}_{1} / \mathrm{ET}_{2}$ has higher airborne dust mass L/I ratios (for feeding period: $0.73-0.87$; for nonfeeding period: $0.71-0.79$ )

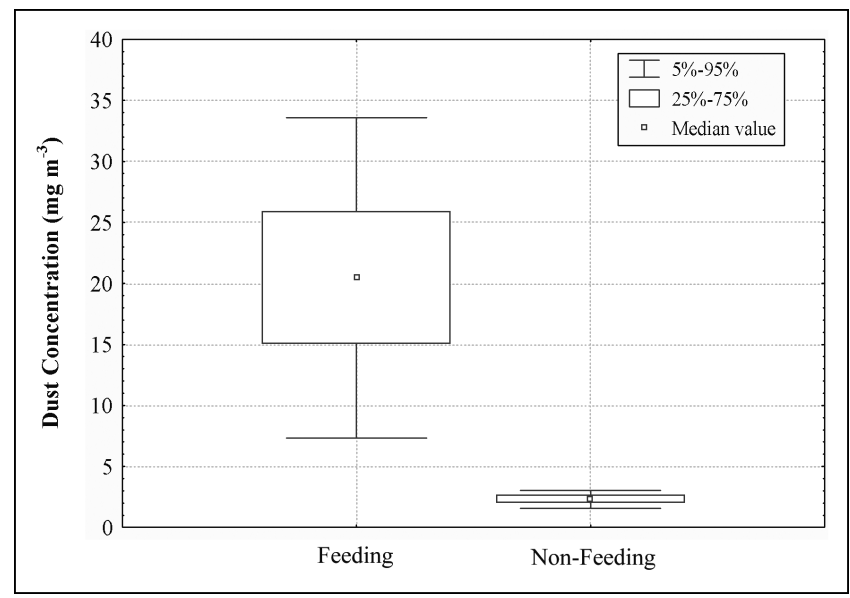

Figure 3. Experimental results of airborne dust concentrations in the Tainan swine building during feeding and nonfeeding periods. Box and whisker show the uncertainty.

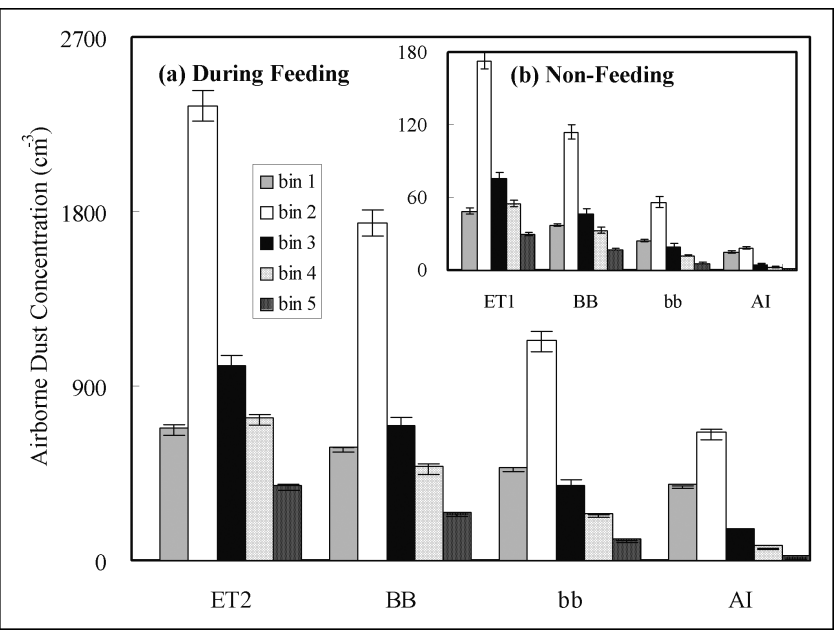

Figure 4. Airborne dust number concentrations of each size range in $H R T$ : (a) during feeding, the lung region includes $\mathrm{ET}_{2}, \mathrm{BB}, \mathrm{bb}$, and $\mathrm{Al}$; and (b) nonfeeding period, the lung region includes $\mathrm{ET}_{1}, \mathrm{BB}, \mathrm{bb}$, and $\mathrm{Al}$.

than that of lung regions BB (for feeding period: $0.47-$ 0.74; for nonfeeding period: 0.41-0.59), bb (for feeding period: 0.21-0.61; for nonfeeding period: 0.12-0.39), and AI (for feeding period: 0.05-0.49; for nonfeeding period: 0.01-0.24) for each bin size in that larger bin sizes have smaller airborne dust mass L/I ratios (Figure 5). The feeding and nonfeeding periods have similar distribution patterns of airborne dust mass L/I ratios. Generally, the GMDs of particle-size distributions of airborne dust in lung regions during a feeding period are larger than during nonfeeding periods (Figure 6). Figure 6 also illustrates the integrated deposition fractions in different HRT regions. This is because the breathing rate of a feeding period is higher than that in a nonfeeding period. A lower breathing rate keeps the airborne dust in HRT for a longer time and results in a higher deposition behavior. Table 4 summarizes the steady-state mass and number concentrations in different HRT regions.

\section{DISCUSSION}

The dominant deposition mechanism in HRT is found to be the inertial impaction rate, in which the deposition rate increased with both increasing dust sizes and decreasing airway diameters. The orders of magnitude of turbulent diffusive deposition, gravitational settling, and inertial impaction rate are $10^{-5}-10^{-3}, 10^{-3}-10^{-2}$, and $10^{-3}$ $10^{0} \mathrm{sec}^{-1}$, respectively, for particle sizes in the range of 0.5-5 $\mu \mathrm{m}$ AED. The calculated results show that the smaller dust has the higher turbulent diffusive deposition rate in all the HRT regions, especially in the deep lung region. The ultrafine dust (with submicrometer or nanometer diameter) may lead to greater turbulent diffusive deposition, which makes the airborne dust deposit to airway walls. Based on simulations, the interception deposition efficiency is relative small compared with the 

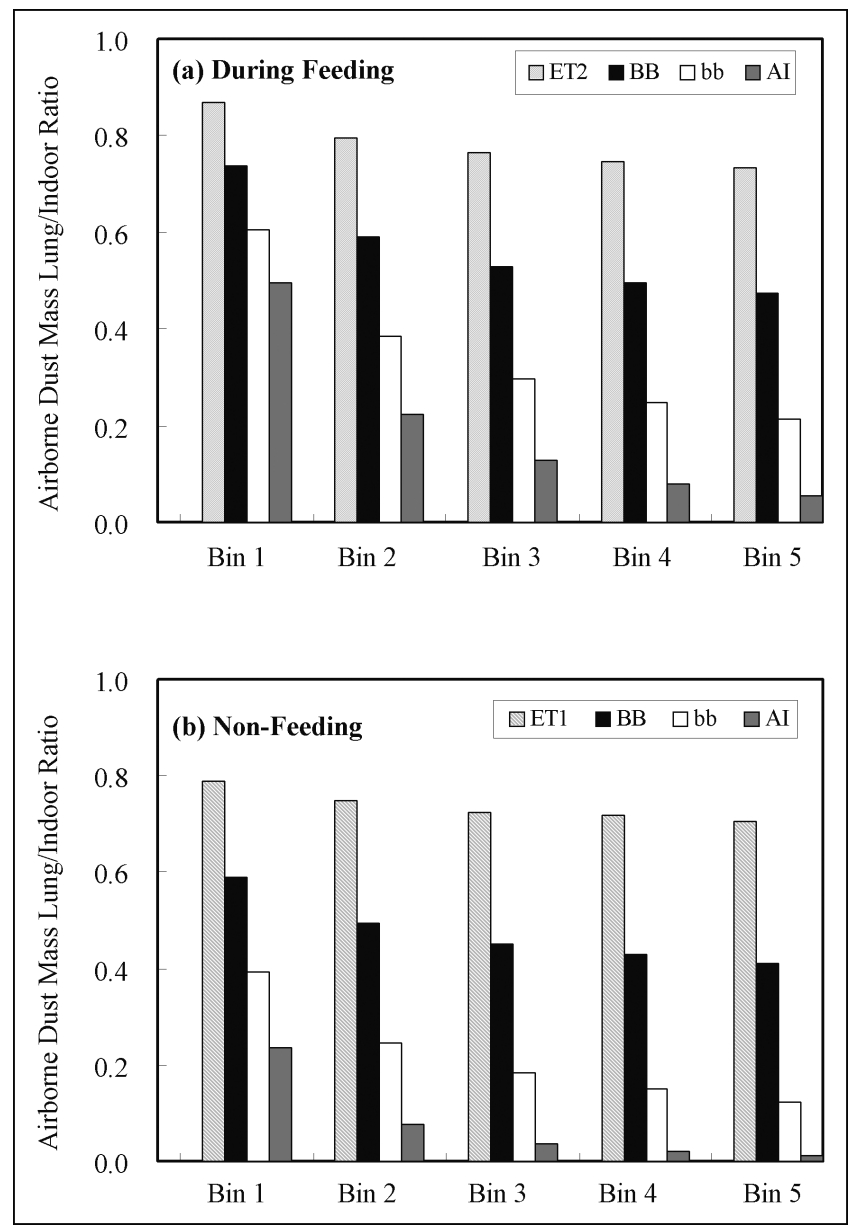

Figure 5. Calculated airborne dust mass $L / /$ ratios for each size bin in HRT during feeding and nonfeeding periods.

other deposition rates. The orders of magnitude of interception deposition efficiency are $10^{-10}-10^{-4} \%$ in all the HRT regions, and may be neglected based on the

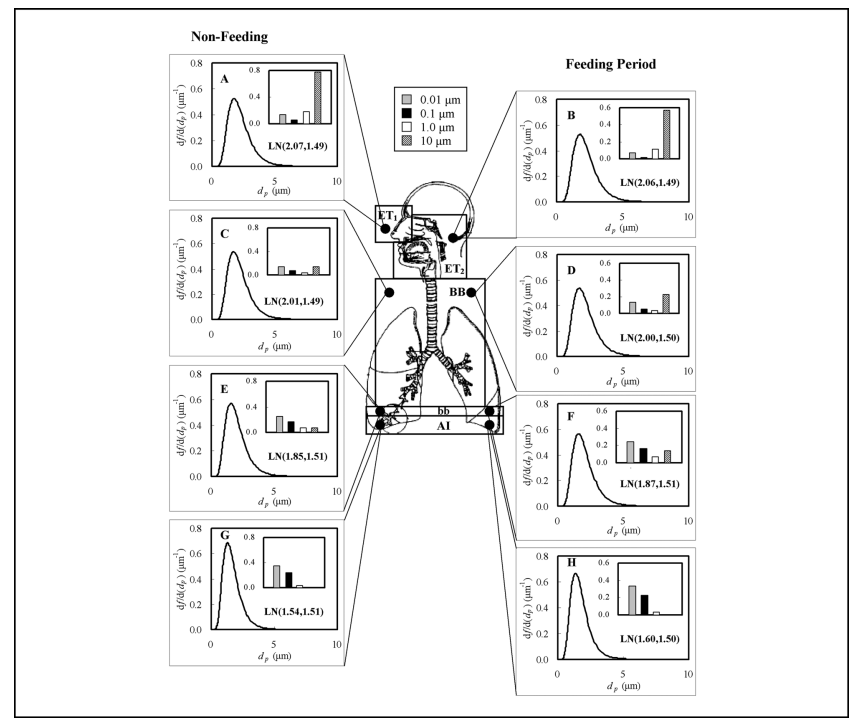

Figure 6. Airborne dust size distribution $[\mathrm{LN}(\mu, \sigma)]$ and distribution of contributions of deposition fractions in different HRT regions.
Table 4. The steady-state airborne dust mass and number concentrations for different regions in HRT during feeding and nonfeeding periods.

\begin{tabular}{lcc}
\hline \hline HRT Region & $\begin{array}{c}\text { Dust Mass } \\
\text { Concentration } \\
\left(\mathbf{m g} / \mathbf{m}^{\mathbf{3}}\right)\end{array}$ & $\begin{array}{c}\text { Dust Number } \\
\text { Concentration } \\
\mathbf{( c m}^{-3} \mathbf{)}\end{array}$ \\
\hline Feeding period & & \\
$\mathrm{ET}_{2}$ & 25.39 & 5155 \\
$\mathrm{BB}$ & 17.21 & 3754 \\
$\mathrm{bb}$ & 9.08 & 2360 \\
$\mathrm{Al}$ & 3.58 & 1330 \\
Non-feeding & & \\
$\mathrm{ET}$ & & 438 \\
$\mathrm{BB}$ & 2.2 & 285 \\
bb & 1.34 & 134 \\
$\mathrm{Al}$ & 0.51 & 44 \\
\hline \hline
\end{tabular}

mathematical point of view. Interception deposition efficiency is considered to be an efficient deposition mechanism only for elongated and fibrous particles and is neglected in the situation of the smallness of $2 d_{\mathrm{p}} / D_{\mathrm{i}} \ll 1 .{ }^{28}$

Theoretical predictions were compared with independently published experimental data, which were obtained by state-of-the-art techniques and are considered to be very reliable data, obtained from ICRP $66^{29}$ and other different studies $28,37-42$ that are referred to as Non-ICRP66 (Figure 7a). Although experimental data are quite scattered, owing both to no consistency in methodology and to parameter variability, model predictions are in

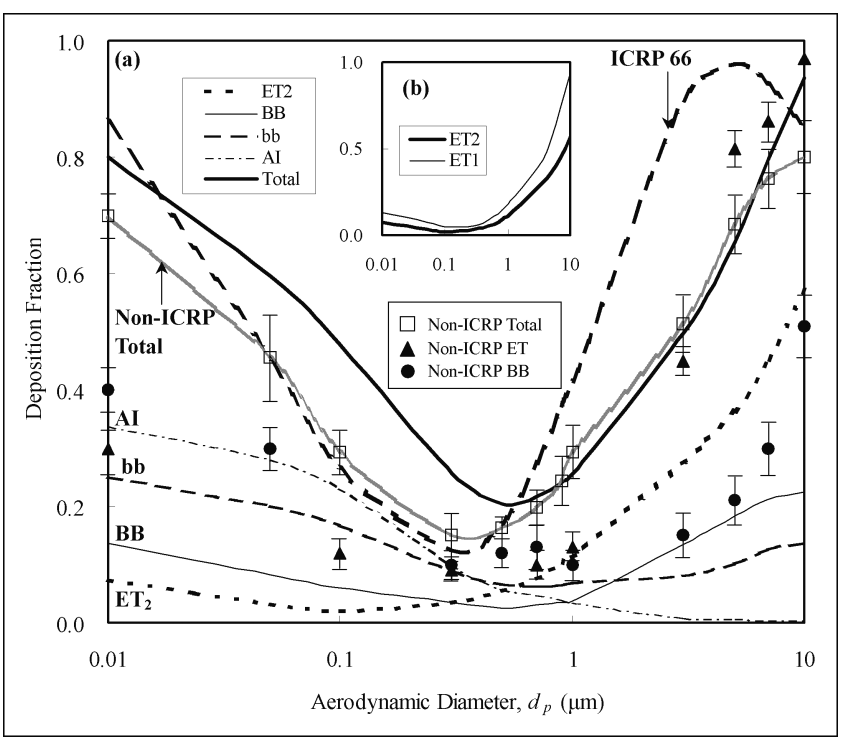

Figure 7. Comparison of nasal passage $\left(E T_{1}\right)$, pharynx $\left(E T_{2}\right)$, bronchial (BB), bronchiolar (bb), and alveolar-interstitial (Al) regions deposition data from ICRP66 and non-ICRP66 with theoretical predictions. Model parameters include a branching angle of $45^{\circ}$, a tidal volume of $1330 \mathrm{~cm}^{3}$, and a breathing frequency of $15 \mathrm{~min}^{-1}$ with initial dust size distribution of a geometric mean diameter $2.17 \mu \mathrm{m}$ and a geometric standard deviation 1.75 . 
qualitative and quantitative agreement with the experimental deposition profile in the $\mathrm{ET}_{2}, \mathrm{BB}, \mathrm{bb}$, and $\mathrm{AI}$ regions (the rms errors of the total deposition fraction between the predicted values and ICRP66 and Non-ICRP66 are 0.15 [15\%] and 0.07 [7\%], respectively). The comparisons between predicted and measured lung deposition profiles suggest that the model seems to be adequate in describing the upper and lower deposition bounds. It can be seen that the maximal regional deposition for all compartments occurs in the AI region in diameter between 0.01 and $0.5 \mu \mathrm{m}$ and occurs in the $\mathrm{ET}_{2}$ region in diameter between 0.5 and $10 \mu \mathrm{m}$. The total deposition rate increased with increasing particle size in the size ranges $0.5-5 \mu \mathrm{m}$. For the same reason described, breathing via the nose has a higher deposition fraction in the size ranges $0.01-10 \mu \mathrm{m}$ than does breathing orally (Figure $7 \mathrm{~b}$ ). It is interesting to note that the deposition may be caused by filtration mechanisms of the $\mathrm{ET}_{1}$ region, ${ }^{14,28,38,41}$ so that the simulated deposition fraction (without taking into account the filtration) among the considered diameter ranging $0.5-5 \mu \mathrm{m}$ in the ET region are lower than that of the experimental results. Most coarse dusts inspired are, therefore, already trapped in nasal passages and, thus, do not reach the lung.

The cumulative dose continues to increase while the feeding begins and the equilibrium occurs in $\sim 9-11$ hr exposure time in all lung regions (Figure 8). The lung region $\mathrm{BB}$ has a higher cumulative dose in per airway wall surface than do lung regions $\mathrm{ET}_{2}$, bb, and AI. The equilibrium exposure doses of airborne dust are 1600, 2000,700 , and $1.5 \mu \mathrm{g} / \mathrm{cm}^{2}$, respectively, in lung regions $\mathrm{ET}_{2}, \mathrm{BB}, \mathrm{bb}$, and AI. The airways of AI compartments have a much larger wall surface than do lung regions $\mathrm{ET}_{2}, \mathrm{BB}$, and $\mathrm{AI}$, and it makes the magnitude of dust

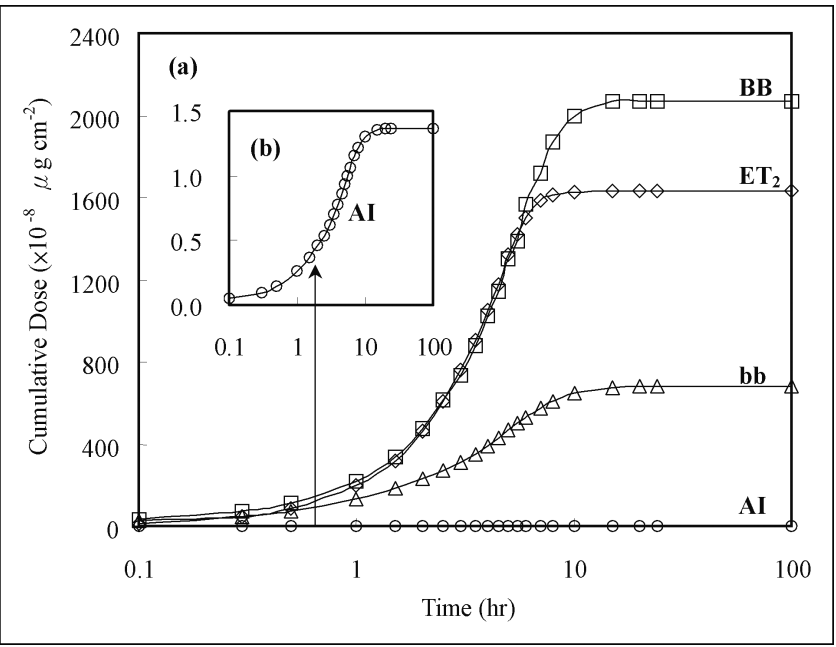

Figure 8. Time-dependent inhalation dose of airborne dust from simulation of the Tainan swine building during feeding. mass deposit on the wall much lower in AI than in other lung regions.

For relatively high temperature differences larger than $20^{\circ} \mathrm{C}$, thermophoresis has a pronounced effect on the size distribution evolution, enhancing deposition along the airways. ${ }^{28}$ Thermophoretic deposition of airborne dust in HRT is not considered in this work because of the temperature differences within $7{ }^{\circ} \mathrm{C}$ between airway wall (assuming a constant temperature of $36{ }^{\circ} \mathrm{C}$ ) and indoor ambient space (the measured temperature is 29 $\left.{ }^{\circ} \mathrm{C}\right)$. The thermophoresis is neglected not only because of a relative small temperature difference but also because of the smaller effect compared with the other deposition mechanisms (e.g., inertial impaction and gravitational settling). ${ }^{34}$

Airborne dust may undergo some hygroscopic growth in a high-humidity environment (e.g., in the HRT). Therefore, when the airborne dust enters the lung, the amount of possible growth depends on how close the relative humidity in swine buildings is to $100 \%$ and further alters the deposition patterns within the lung. The hygroscopic growth of airborne dust was obtained ${ }^{38}$ in that the ambient relatively humidity is $60 \%$ (in this work, the ambient relatively humidity of the Tainan swine building is 65\%) in region ET, whereas the difference of deposition fractions between hygroscopic and nonhygroscopic are $0.14,0.08$, and 0.02 in dust diameters of $0.5,1$, and $5 \mu \mathrm{m}$, respectively.

Protective measures, designed to prevent airway disease in swine houses, should be based on information about the operational and other characteristics of farms that are related to high exposure and health effects. The use of personal respiratory devises is limited in agricultural operations because they are hot and uncomfortable and are not routinely worn. National Institute for Occupational Safety and Health (NIOSH)-approved two-strap dust and mist respirators are adequate for prevention when working in dusty and moldy conditions. ${ }^{43}$ Studies have shown that the two-strap masks were effective in preventing further attacks of hypersensitivity pneumonitis (FHP). ${ }^{44}$ Engineering controls are preferable to longterm use of personal respiratory protection. Methods of control include decreasing dust generation by adding mist, adding vegetable oil to feed, sprinkling oil on the animals, and using wet methods to clean surfaces. ${ }^{45}$ The use of canola oil sprinkled in a swine room significantly decreased adverse respiratory effects in human subjects and concomitantly decreased dust, endotoxin levels, and toxic gases. ${ }^{46,47}$ Fats added to feeds in the form of canola oil, rapeseed, and mineral oil decreased dust levels by $35-60 \%$ in swine confinement buildings. ${ }^{48}$ Ventilation with proper mixing of air improves air quality by decreasing dust and gas levels. 
The proposed simple lung model provides an easy yet robust way to account for and keep track of the contribution of different processes of lung deposition profiles, even though the model is based on many idealized assumptions, such as one-dimensional airflow and single morphological change. The approach also can examine independently the processes and mechanisms that govern the inhalation route of the exposure-dose-response scenario.

\section{CONCLUSIONS}

Experimental results show that there is no significant variation in feeding and nonfeeding periods for the particle size distributions in swine buildings located in the southern region of Taiwan. For simulations in feeding and nonfeeding periods, 95th-percentile prediction values of dust concentrations were employed. The dominant deposition mechanism in the lung regions was found to be the inertial impaction rate, in which the order of magnitude ranged from $10^{-3}$ to $10^{-1} \mathrm{sec}^{-1}$. Results demonstrate that the extrathoracic region has higher airborne dust mass L/I ratios $(0.71-0.87)$ than do bronchial regions (0.41-0.74), the bronchiolar region (0.12-0.61), and the AI region (0.01-0.49). Comparison of human respiratory tract (HRT) deposition data from ICRP66 and Non-ICRP66 with theoretical predictions indicate that predictions are in agreement with the experimental deposition profiles in lung regions, whereas the rms errors of the total deposition fraction between predicted values and ICRP66 and Non-ICRP66 are 0.15 and 0.07 , respectively. In addition, simulation results show that breathing via the nose has a higher deposition fraction in the size ranges $0.01-10 \mu \mathrm{m}$ than does breathing orally.

Because of a lack of sufficient airway measurements, idealized airway structures are used for the lung region. It is necessary to include biological variability information for individual subjects to define the population-wide lung dosimetry resulting from dust intakes. Unlike clinical methods, mathematical models provide an efficient option for analysis of lung deposition, which may be used for regulatory policy development in the fields of industrial hygiene and environmental and occupational health in predicting the dose resulting from exposure via inhalation to airborne pollutants.

\section{APPENDIX}

\section{Nomenclature}

$A_{\mathrm{i}} \quad$ Surface area of airway wall in the lung region $i$ $\left(\mathrm{cm}^{2}\right)$

$[B] \quad$ Constant input matrix $\left(\mathrm{sec}^{-1}\right)$

$\{C(k, t)\} \quad$ State variable vector of airborne dust concentration in lung regions $\left(\mu \mathrm{g} / \mathrm{cm}^{3}\right)$
$C_{I}(k, t) \quad$ Time dependent indoor airborne dust concentration in the $k^{\text {th }}$ size range $\left(\mathrm{kg} / \mathrm{m}^{3}\right)$

$C_{\text {slip }} \quad$ Slip correlation factor (dimensionless)

$D\left(d_{\mathrm{p}}\right) \quad$ Brownian diffusion coefficient $\left(\mathrm{m}^{2} / \mathrm{sec}\right)$

$D_{\mathrm{i}} \quad$ Diameter of airways $(\mathrm{cm})$

$d_{\mathrm{F}}(k) \quad$ Airborne dust deposition fraction in the $k$ th size range

$d_{\mathrm{k}}, d_{\mathrm{k}+1}$ End point diameter for a $k$ th size range

$d_{\max } \quad$ Largest dust diameter $(\mu \mathrm{m})$

$d_{\text {min }} \quad$ Minimum dust diameter $(\mu \mathrm{m})$

$d_{\mathrm{p}} \quad$ Airborne dust diameter $(\mu \mathrm{m})$

g Gravitational acceleration constant $\left(\mathrm{m} / \mathrm{sec}^{2}\right)$

$\mathrm{Ku} \quad$ Kawabara parameter

$k \quad$ Size range number

$k_{\mathrm{B}} \quad$ Boltzmann's constant

$k_{\mathrm{e}} \quad$ Turbulent intensity parameter $\left(\mathrm{sec}^{-1}\right)$

[L] State matrix $\left(\mathrm{sec}^{-1}\right)$

$N \quad$ The end point number for a $k$ th size range

$n \quad$ Exponent constant

$n_{\mathrm{i}} \quad$ Number of airways

Q Breathing rate $\left(\mathrm{cm}^{3} / \mathrm{hr}\right)$

$Q_{\mathrm{f}} \quad$ Breathing frequency $\left(\mathrm{min}^{-1}\right)$

Stk Stokes number

$\mathrm{T} \quad$ Ambient absolute temperature $\left({ }^{\circ} \mathrm{K}\right)$

$U_{\mathrm{i}} \quad$ Airflow velocity of airways ( $\mathrm{m} / \mathrm{sec}$ )

$\{u(k, t)\} \quad$ Input vector of indoor airborne dust concentrations $\left(\mu \mathrm{g} / \mathrm{cm}^{3}\right)$

$V_{\mathrm{i}} \quad$ Volume of compartments

$v_{\mathrm{s}}\left(d_{\mathrm{p}}\right) \quad$ Settling velocity $(\mathrm{m} / \mathrm{sec})$

$\alpha \quad$ Bifurcation of airways

$\beta_{\mathrm{mn}} \quad$ Transition coefficient from lung compartment $n$ to $m$

$\varepsilon_{\mathrm{i}}(k) \quad$ Interception deposition efficiency in the $k$ th size range in lung $i$

$\eta_{\mathrm{a}} \quad$ Dynamic viscosity of air $(\mathrm{g} / \mathrm{cm} / \mathrm{sec})$

$\rho_{\mathrm{a}} \quad$ Density of the air $\left(\mathrm{g} / \mathrm{cm}^{3}\right)$

$\rho_{\mathrm{p}} \quad$ Particle density $\left(\mathrm{g} / \mathrm{cm}^{3}\right)$

$\lambda \quad$ Mean free path of air $(\mathrm{cm})$

$\lambda_{\mathrm{d}}(k) \quad$ Deposition rate in the $k$ th size range $\left(\mathrm{sec}^{-1}\right)$

$\lambda_{\mathrm{di}}(k) \quad$ turbulent diffusive deposition rate in the $k$ th size range in the lung region $i\left(\mathrm{sec}^{-1}\right)$

$\lambda_{\mathrm{mni}}(k) \quad$ Inertial impaction rate in the $k$ th size range in the lung region $i\left(\mathrm{sec}^{-1}\right)$

$\lambda_{\mathrm{L}}(t) \quad$ Airborne dust clearance rate in region AI $\left(\mathrm{sec}^{-1}\right)$

$\lambda_{\mathrm{si}} \quad$ Gravitational settling rate in the $k$ th size range in lung region $i\left(\mathrm{sec}^{-1}\right)$

\section{ACKNOWLEDGMENTS}

The authors wish to acknowledge the financial support of the National Science Council of the Republic of China under Grant NSC 92-2313-B-002-103. 


\section{REFERENCES}

1. Liao, C.M.; Chen, J.W.; Huang, M.Y.; Chen, J.S. Chang, T.J. An Inhalation Dose Model for Assessing Dust-Borne VOC-Odor Exposure from Feeding in Swine Buildings; Trans. ASAE 2001, 44, 1813-1824.

2. Riskowski, G.L.; Marghirang, R.G.; Funk, T.L.; Christianson, L.L.; Priest, J.B. Environment Quality in Animal Housing Facilities-A Review and Evaluation of Alternative Ventilation Strategies; Final report to the ASHRAE; ASHRAE: Atlanta, GA, 1995.

3. Predicala, B.Z.; Maghirang, R.G.; Jerez, S.B.; Urban, J.E.; Goodband, R.D. Dust and Bioaerosol Concentrations in Two Swine-Finishing Buildings in Kanasa; Trans. ASAE 2001, 44, 1291-1298.

4. Zhang, Y.; Tanaka, A.; Barber, E.M.; Feddes, J.J.R. Effects of Frequency and Quantity of Sprinkling Canola Oil on Dust Reduction in Swine Buildings; Trans. ASAE 1996, 39 (3), 1077-1081.

5. Perkins, S.L.; Feddes. J.J.R. The Effects of Timing of Floor-Application of Mineral Oil on Dust Concentrations in a Swine Farrowing Unit; Can. Agric. Eng. 1996, 38, 123-127.

6. Gao, W.; Feddes, J.J.R. Using Swine Dust to Verify a Lumped-Parameter Model in a Ventilated Enclosure; Can. Agric. Eng. 1993, 35, 67-73.

7. Van Wicklen, G.L.; Yoder, M.F. Respirable Aerosol Concentrations in an Enclosed Swine Nursery; Trans. ASAE 1988, 31, 1798-1803.

8. Van Wicklen, G.L.; Foutz, T.L.; Rowland, G.N. Respirable Tissue Damage in Broilers Exposed to Aerosol Particles and Ammonia; Trans. ASAE 2001, 44, 1889-1994.

9. Maghirang, R.G.; Puma, M.C.; Liu, Y.; Clark, P. Dust Concentrations and Particle Size Distribution in an Enclosed Swine Nursery; Trans. ASAE 1997, 40, 749-754.

10. Linaker, C.; Smedley, J. Respiratory Illness in Agricultural Workers; Occup. Med. 2002, 52, 451-459.

11. Radon, K.; Danuser, B.; Iversen, M. Respiratory Symptoms in European Animal Farmers; Eur. Respir. J. 2001, 17 (4), 747-754.

12. Åhman, M.; Holmström, M.; Kolmodin-Hedman, B.; Thelin, A. Nasal Symptoms and Pathophysiology in Farmers; Int. Arch. Occup. Environ. Health 2001, 74, 279-284.

13. Radon, K.; Weber, C.; Iversen, M.; Danuser, B.; Pedersen, S.; Nowak, D. Exposure Assessment and Lung Function in Pig and Poultry Farmers; Occup. Environ. Med. 2001, 58, 405-410.

14. Donham, K.J.; Gustafson, K.E. Human Occupational Hazards from Swine Confinement; Ann. Am. Conf. Gov. Ind. Hyg. 1982, 2, 137-142.

15. Crook, B.; Robertson, J.F.; Travers, S.A.; Botheroyd, E.M.; Lacey, J.; Topping, M.D. Airborne Dust, Ammonia, Microorganisms, and Antigens in Pig Confinement Houses and the Respiratory Health of Exposed Farm Workers; Am. Ind. Hyg. Assoc. J. 1999, 52, 271-279.

16. Olson, D.K.; Bark, S.M. Health Hazards Affecting the Animal Confinement Farm Worker; Am. Assoc. Occup. Health Nur. J. 1996, 44, 198-204.

17. Vogelzang, P.F.J.; van der Gulden, J.W.J.; Preller, L.; Tielen, M.J.M.; Schayck, C.P.; Folgering, H. Bronchial Hyperresponsiveness and Exposure in Pig Farmers; Int. Arch. Occup. Envir. Health 1997, 70, $327-$ 333.

18. Donham, K.J.; Popendorf, W. Ambient Levels of Selected Gases inside Swine Confinement Buildings; Am. Ind. Hyg. Assoc. J. 1985, 46, 658661.

19. Heederik, D.; Brouwer, R.; Biersteker, K.; Boleij, J.S.M. Relationship of Airborne Endotoxin and Bacteria Levels in Pig Farms with the Lung Function and Respiratory Symptoms of Farmers; Int. Arch. Occup. Envir. Health 1991, 62, 595-601.

20. Zejda, J.E.; Barber, E.; Dosman, J.A.; Olenchock, S.A.; McDuffie, H.H.; Rhodes, C.; Hurst, T. Respiratory Health Status in Swine Producers Related to Endotoxin Exposure in the Presence of Low Dust Levels; $J$. Occup. Med. 1994, 36, 49-56.

21. Reynolds, S.J.; Donham, K.J.; Whitten, P.; Merchant, J.A.; Burmeister, L.F.; Popendorf, W.J. Longitudinal Evaluation of Dose-Response Relationships for Environmental Exposures and Pulmonary Function in Swine Production Workers; Am J. Ind. Med. 1996, 29, 33-40.

22. Donham, K.J.; Haglind, P.; Peterson, Y.; Rylander, R.; Berlin, L. Environmental and Health Studies of Farm Workers in Swedish Swine Confinement Buildings; $\mathrm{Br}$. J. Ind. Med. 1989, 46, 31-37.

23. Donham, K.J.; Reynolds, S.J.; Whitten, P.; Merchant, J.A.; Burmeister, L.F.; Popendorf, W.J. Respiratory Dysfunction in Swine Production Facility Workers: Dose-Response Relationships of Environmental Exposures and Pulmonary Function; Am. J. Ind. Med. 1995, 27, 405-418.

24. Pope, C.A.; Dockery, D.W. Acute Health Effects of $\mathrm{PM}_{10}$ Pollution on Symptomatic and Asymptomatic Children; Amer. Rev. Respir. Dis. 1992, 145, 1123-1128.

25. Dockery, D.W.; Pope, C.A.; Xu, X.P.; Spengler, J.D.; Ware, J.H.; Fay, M.E.; Ferris, B.G.; Speizer, F.E. An Association between Air Pollution and Mortality in 6 United States; New Engl. J. Med. 1993, 329, 17531759.

26. Schwartz, J. Air-Pollution and Daily Mortality in Birmingham, Alabama; Am. J. Epidemiol. 1993, 137 (10), 1136-1147.

27. Seaton, A.; MacNee, W.; Donalden, K.; Godden, D. Particulate Air Pollution and Acute Health Effects; Lancet 1995, 345, 176-178.
28. Lazaridis, M.; Broday, D.M. Hov, Ø.; Georgopoulos, P.G. Integrated in the Human Respiratory Tract; Environ. Sci. Technol. 2001, 35, 37273734 .

29. ICRP. Human Respiratory Tract Model for Radiological Protection, A Report of a Task Group of the International Commission on Radiological Protection, ICRP Publication No. 66; Elsevier: New York, 1994.

30. Jacquez, J.A. Compartmental Analysis in Biology and Medicine, 3rd ed.; Thomson-Shore: West Joy Road, Dexter, 1996.

31. Crump, J.G.; Seinfeld, J.H. Turbulent Deposition and Gravitational Sedimentation of an Aerosol in a Vessel of Arbitrary Shape; J. Aerosol Sci. 1981, 12, 405-415.

32. Nazaroff, W.W.; Cass, G.R. Mass-Transport Aspects of Pollutant Removal at Indoor Surfaces; Environ. Int. 1989, 15, 567-584.

33. Nazaroff, W.W.; Ligocki, M.P.; Ma, T.; Cass, G.R. Particle Deposition in Museums: Comparison of Modeling and Measurement Results; Aerosol Sci. Technol. 1990, 13, 332-348.

34. Hinds, W.C. Aerosol Technology: Properties, Behavior, and Measurement of Airborne Particles, 2nd ed.; John Wiley: New York, 1999.

35. Zar, J.H. Biostatistical Analysis, 4th ed.; Prentice-Hall: New Jersey, -.

36. IMSL MATH/LIBRARY. FORTRAN Subroutine for Mathematical Applications, Vol. 1; Visual Numerics: Houston, TX, 1994.

37. Yu, C.P.; Diu, C.K. Total and Regional Deposition of Inhaled Aerosols in Humans; J. Aerosol Sci. 1983, 14, 599-609.

38. Sarangrapani, R.; Wexler, A.S. Modeling Particle Deposition in Extrathoracic Airways; Aerosol Sci. Technol. 2000, 32, 72-89.

39. Hofmann, W.; Bergmann, R.; Balásházy, I. Variability and Inhomogeneity of Radon Progeny Deposition Patterns in Human Bronchial Airways; J. Environ. Radioact. 2000, 51, 121-136.

40. Asgharian, B.; Hofmann, W.; Bergmann, R. Particle Deposition in a Multi-Path Model of the Human Lung; Aerosol Sci. Technol. 2001, 34, 332-339.

41. Salma, I.; Balásházy, I.; Winkler-Heil, R.; Hofmann, W.; Záray, G. Effect of Physical Exertion on the Deposition of Aerosols in the Human Respiratory System; J. Aerosol Sci. 2002, 33, 983-997.

42. Hofmann, W.; Asgharian, B.; Winkler-Heil, R. Modeling Intersubject Variability of Particle Deposition in Human Lungs; J. Aerosol Sci. 2002, 33, 219-235.

43. Pickrell, J.A.; Heber, A.J.; Murphy, J.P.; May, M.M.; Nolan, D.; Gearhart, S.K.; Cederberg, B.I.; Oehme, F.W.; Schoneweis, D. Total and Respirable Dust in Swine Confinement Buildings: The Benefit of Respiratory Protective Masks and Effect of Recirculated Air; Vet. Human Toxicol. 1995, 37, 430-435.

44. Ohtsuka, Y.; Munukata, M.; Tanimura; Ukita, H.; Kusaka, H. Smoking Promotes Insidious and Chronic Farmer's Lung Disease and Deteriorates the Clinical Outcome; Intern. Med. 1995, 34, 966-971.

45. Pearson, C.C.; Sharples, T.J. Airborne Dust Concentrations in Livestock Buildings and Effect of Feeds; J. Agric. Eng. Res. 1995, 60, 145154.

46. Senthilselvan, A.; Zhang, Y.; Dosman, J.A.; Barber, E.M.; Holfeld, L.E.; Kirychuk, S.P.; Cormier, Y.; Hurst, T.S.; Rhodes, C.S. Positive Human Health Effects of Dust Suppression with Canola Oil in Swine Barns; Am. J. Respir. Crit. Care Med. 1997, 156, 410-417.

47. Zhang, Y. Sprinkling Oil to Reduce Dust, Gases, and Odor in Swine Buildings; Agric. Eng. Digest. 1997, 42, 1-8.

48. Takai, H.; Jacobson, L.; Pederson, S. Reduction of Dust Concentrations and Exposure in Pig Buildings by Adding Animal Fat in Feed; J. Agric. Eng. Res. 1996, 63, 113-120.

\section{About the Authors}

Jein-Wen Chen received his Ph.D. from the Department of Bioenvironmental Systems Engineering at National Taiwan University in June 2003. Chung-Min Liao is a professor and Szu-Chieh Chen is a master graduate assistant in the Biosystems Modeling and Control Lab, Department of Bioenvironmental Systems Engineering at National Taiwan University in Taipei, Taiwan. Address correspondence to: Dr. Chung-Min Liao, Department of Bioenvironmental Systems Engineering, National Taiwan University, Taipei, Taiwan 10617; fax: 886-2-2362-6433; e-mail: cmliao@ntu.edu.tw. 